\title{
PENGUKURAN KINERJA RANTAI PASOK \\ DENGAN PENDEKATAN SUPPLY CHAIN OPERATION REFERENCE (SCOR) PADA KELOMPOK TANI DI PACITAN \\ MEASUREMENT OF SUPPLY CHAIN PERFORMANCE WITH SUPPLY CHAIN OPERATION REFERENCE (SCOR) APPROACH ON TANI GROUP IN PACITAN
}

\author{
Adi Budiwan $^{1)}$ dan Ramon Syahrial ${ }^{2)}$ \\ ${ }^{1)}$ Jurusan Agribisnis, Fakultas Pertanian, Universitas Wijaya Putra Surabaya \\ Email: adibudiwan9@gmail.com
}

\begin{abstract}
ABSTRAK
Tujuan penelitian ini adalah merancang sistem pengukuran kinerja rantai pasok serta memberikan usulan perbaikan berdasarkan hasil pengukuran kinerja rantai pasoknya. Penelitian dilakukan pada kelompok tani di Kabupaten Pacitan. Hasil rancangan pengukuran kinerja rantai pasok adalah 24 KPI yang dibagi ke dalam lima proses manajemen dasar rantai pasok, yaitu: plan, source, make, deliver dan return. Identifikasi KPI diperoleh dari kerangka SCOR model. Dengan konsep AHP diperoleh bobot untuk masing-masing perspektif yaitu plan $(0,233)$; source $(0,120)$; make $(0,555)$, deliver $(0,060)$ dan return $(0,032)$. Pada tahap pengukuran, proses scoring system menggunakan proses normalisasi Snom De Bour, selanjutnya dengan analisis traffic light system yaitu untuk mengetahui pencapaian performasi KPI melalui tiga warna (merah, kuning dan hijau) sebagai indikator. Dari hasil pengukuran performansi terdapat 2 KPI yang memiliki kinerja rendah yang memerlukan prioritas perbaikan yaitu Product Failure in Grinding Process (PFGP) dan Product Failure in Mixer Process (PFMP).
\end{abstract}

Kata Kunci: Pengukuran, Performansi, Rantai, SCOR, Model, Process

\section{ABSTRACT}

The purpose of this study is to design a supply chain performance measurement system and provide improvement proposals based on the results of the supply chain performance measurement. This research was conducted on farmer groups in Pacitan district. The results of this supply chain performance measurement design are 24 KPIs which are divided into five basic supply chain management processes, namely: plan, source, make, deliver and return. KPI identification is obtained from the SCOR model framework. With the AHP concept we obtain weights for each perspective, namely plan $(0.233)$; source $(0,120)$; make $(0.555)$, deliver $(0.060)$ and return (0.032). At the measurement stage, the scoring system process uses the Snom De Bour normalization process, then the traffic light system analysis is to find out the achievement of KPI performance through three colors (red, yellow and green) as indicators. From the results of performance measurement there are 2 KPIs that have low performance, which require priority improvements, namely Product Failure in Grinding Process (PFGP) and Product Failure in Mixer Process (PFMP).

Keywords: Measurement, Performance, Chain, Scor, Model, Process 


\section{PENDAHULUAN}

Manajemen rantai pasok meliputi seluruh aktivitas mulai material datang dari supplier, material diolah menjadi produk setengah jadi dan selanjutnya produk didistribusikan ke konsumen. Untuk mengetahui kinerja suatu usaha diperlukan pengukuran di mana pengukuran tersebut memerlukan kerangka atau model. Selama ini model pengukuran untuk kinerja rantai pasok bersifat fragmented yang artinya masih terpisah-pisah misalnya dilihat dari sisi bahan bakunya saja, segi produksinya saja atau segi sistem informasinya saja. Pengukuran tersebut dipandang belum tepat dan belum baik. Oleh karena itu diperlukan pengukuran yang holistik dan terintegrasi sehingga diperoleh model pengukuran yang valid.

\section{Supply Chain Management} merupakan sebuah jaringan supplier, manufaktur, perakitan, distribusi dan fasilitas logistik yang membentuk fungsi pembelian dari material transformasi material menjadi barang setengah jadi maupun produk jadi serta proses distribusi dari produkproduk tersebut ke konsumen (Pires et.al., 2011). Sedangkan tujuan dari
SCM menurut Pujawan (2015) adalah memaksimalkan hubungan potensial antar bagian dalam rantai pasok untuk memberikan yang terbaik bagi konsumen dan mengurangi biaya produk akhir.

Berkaitan dengan masalah pengukuran kinerja rantai pasok, Klapper dan Hamblin (2010) mengatakan bahwa dalam pengukuran kinerja rantai pasok terdapat dua bagian utama yaitu pengukuran kinerja itu sendiri dan analisa terhadap hasil pegukuran kinerja. Menurut Chopra dan Peter (2011) pengukuran kienerja dan analisanya dapat digunakan sebagai: (1) memberikan pandangan yang luas dalam proses rantai pasok dan cara perbaikannya, (2) memberikan pandangan mengenai permintaan dalam proses rantai pasok, (3) pengontrol biaya, (4) pengontrol kualitas (5) menentukan level dan pengontrol pelayanan terhadap konsumen.

Selain itu, dikenal juga model SCOR. Model SCOR (Supply Chain Operations References) merupakan cara perusahaan untuk mengkomunikasikan suatu kerangka menjelaskan rantai pasok secara detail, mendefinisikan dan mengkategorikan 
proses yang membangun fungsi rantai pasok (Trienekens dan Hvolby, 2015). Menurut Klapper dan Hamblin (2010) terdapat lima manajemen dasar dari proses SCOR yaitu: (1) PLAN, yaitu proses-proses yang berkaitan dengan perencanaan produksi (keseimbangan antara permintaan aktual dengan yang telah direncanakan) dan persediaan bahan baku maupun produk jadi, (2) SOURCE, yaitu proses yang berkaitan dengan pengadaan bahan baku, supplier dan pembelian bahan baku untuk memenuhi permintaan yang ada, (3) MAKE, yaitu proses yang berkaitan dan transformasi bahan baku menjadi produk setengah jadi maupun produk jadi untuk memenuhi permintaan yang ada, (4) DELIVER, yaitu proses yang berkaitan dengan persediaan barang jadi, termasuk di dalamnya mengenai manajemen transportasi dan warehouse untuk memenuhi permintaan konsumen, (5) RETURN, yaitu proses yang berkaitan dengan pengembalian produk karena alasan tertentu, misalnya produk tidak sesuai dengan permintaan konsumen.

$$
\text { Selain model SCOR, }
$$
Analythical Hierarchy Process (AHP) merupakan salah satu dari metode MCDM yang berperan dalam membuat formulasi dan menganalisa suatu keputusan. Beberapa prinsip dalam metode AHP, antara lain: (1) Penyusunan Hierarki, hierarki adalah abstraksi suatu sistem yang mempelajari fungsi interaksi antara elemen dan dampaknya pada sistem untuk menggambarkan elemen sistem atau alternatif keputusan yang teridentifikasi; (2) Penentuan Prioritas, melakukan perbandingan berpasangan (pairwise comparison) pada setiap kriteria dan alternatif yaitu membandingkan setiap elemen dengan elemen lainnya pada setiap tingkat hierarki secara berpasangan sehingga diperoleh nilai tingkat kepentingan elemen dalam bentuk kuantitatif dengan skala penilaian seperti pada Tabel 1; (3) Konsistensi, tahapan ini menunjukkan intensitas relasi antar elemen didasarkan pada suatu kriteria tertentu. Rasio inkonsistensi merupakan perhitungan matematis untuk setiap perbandingan berpasangan yang menyatakan deviasi konsistensi. 
Tabel 1. Skala Perbandingan Berpasangan pada AHP

\begin{tabular}{|c|c|c|}
\hline $\begin{array}{c}\text { Intensitas } \\
\text { Kepentingan }\end{array}$ & Definisi & Keterangan \\
\hline 1 & $\begin{array}{l}\text { Sama } \\
\text { pentingnya } \\
(\text { equal })\end{array}$ & $\begin{array}{l}\text { Dua elemen } \\
\text { mempunyai } \\
\text { kepentingan } \\
\text { sama }\end{array}$ \\
\hline 3 & $\begin{array}{l}\text { Sedikit } \\
\text { lebih } \\
\text { penting } \\
\text { (moderate) }\end{array}$ & $\begin{array}{l}\text { Elemen yang } \\
\text { satu sedikit } \\
\text { lebih penting } \\
\text { dibanding yang } \\
\text { lain }\end{array}$ \\
\hline 5 & $\begin{array}{l}\text { Lebih } \\
\text { penting } \\
\text { (strong) }\end{array}$ & $\begin{array}{l}\text { Elemen yang } \\
\text { satu lebih } \\
\text { penting } \\
\text { dibanding yang } \\
\text { lain }\end{array}$ \\
\hline 7 & $\begin{array}{l}\text { Jelas lebih } \\
\text { penting } \\
\text { (very } \\
\text { strong) }\end{array}$ & $\begin{array}{l}\text { Elemen yang } \\
\text { satu jelas lebih } \\
\text { penting } \\
\text { dibanding yang } \\
\text { lain }\end{array}$ \\
\hline 9 & $\begin{array}{l}\text { Mutlak } \\
\text { lebih } \\
\text { penting } \\
\text { (extreme) }\end{array}$ & $\begin{array}{l}\text { Elemen yang } \\
\text { satu mutlak } \\
\text { lebih penting } \\
\text { dibanding yang } \\
\text { lain }\end{array}$ \\
\hline $2,4,6,8$ & \multicolumn{2}{|c|}{$\begin{array}{l}\text { Nilai di antara dua yang } \\
\text { berdekatan }\end{array}$} \\
\hline Kebalikan & \multicolumn{2}{|c|}{$\begin{array}{l}\text { Jika elemen i mendapat satu } \\
\text { angka dibandingkan elemen } \mathrm{j} \text {, } \\
\text { maka elemen } \mathrm{j} \text { mempunyai } \\
\text { nilai kebalikan bila } \\
\text { dibandingkan dengan } \mathrm{i}\end{array}$} \\
\hline
\end{tabular}

Untuk mengetahui nilai pencapaian terhadap target yang telah ditetapkan untuk setiap indikator kinerja. Adapun tiga macam jenis skor: (1) Lower is Better (LWB), karakteristik ini meliputi pengukuran di mana semakin rendah nilai (mendekati nol) maka kualitasnya makin baik; (2) Larger is Better (LGB), karakteristik ini meliputi pengukuran di mana semakin tinggi nilai maka kualitasnya makin baik; (3) Nominal is Better, karakteristik ini biasanya ditetapkan suatu nilai nominal tertentu, semakin mendekati nilai nominal tersebut maka kualitasnya semakin baik.

Kelompok tani di Pacitan merupakan kelompok usaha tani yang tidak hanya bercocok tanam, tetapi juga mengolah hasil pertanian menjadi lebih bernilai serta memiliki nilai jual tinggi. Penelitian ini bertujuan untuk merancang sistem pengukuran kinerja rantai pasok pada kelompok tani Pacitan, melakukan pengukuran kinerja rantai pasok pada kelompok tani Pacitan serta memberikan usulan perbaikan berdasarkan hasil pengukuran kinerja rantai pasok pada kelompok tani Pacitan.

\section{METODE PENELITIAN}

\section{Tahap Identifikasi Awal}

Tahap ini merupakan tahap pengumpulan informasi dari studi literatur dan studi lapangan untuk mengidentifikasi serta merumuskan masalah dari latar belakang yang ada, kemudian menentukan tujuan yang hendak dicapai serta menentukan batasan dan asumsi penelitian yang dilakukan. 
Tahap Perancangan Sistem

Pengukuran Kinerja

a. Identifikasi KPI. Mengidentiifikasi KPI berdasarkan SCOR model akan tetapi model SCOR yang dipakai bukan untuk keseluruhan rantai, tetapi hanya untuk internal rantai pasok kelompok usaha.

b. Validasi KPI. Pihak pengelola usaha akan menentukan apakah suatu indikator kinerja telah benarbenar sesuai dengan kondisi dan kebutuhan kelompok usaha.

c. Pembobotan dengan Analythical Hierarchy Process (AHP). Proses pembobotan KPI untuk menyusun hierarki sistem pengukuran performansi rantai pasok.

\section{Tahap Pengukuran dan Analisa Performansi Rantai Pasok}

Pengukuran dimulai dari pemberian tipe KPI dengan scoring system, yaitu untuk mengetahui nilai pencapaian setiap indikator terhadap nilai target yang ditentukan. Setelah itu dilanjutkan penyamaan satuan indikator dengan menggunakan rumus normalisasi dari De Boer dan dilakukan analisa Traffic Light System untuk mengetahui pencapaian kinerja.
Langkah terakhir pada tahap ini adalah analisa kinerja rantai pasok.

\section{Tahap Penarikan Kesimpulan}

Penarikan kesimpulan adalah jawaban dari tujuan. Saran juga diberikan sebagai masukan berkaitan dengan penelitian.

\section{HASIL DAN PEMBAHASAN}

\section{Pemilihan Produk Amatan}

Usaha kelompok tani Pacitan yang diamati adalah usaha penyulingan minyak atsiri yang dalam produksinya menggunakan sistem make to order. Usaha ini dapat berproduksi secara terus-menerus sepanjang tahun sehingga data yang diperlukan dalam penelitian dapat terpenuhi.

\section{a. Sistem Pengukuran Kinerja yang Ada}

Data yang diukur adalah:

1. Production Yield, yaitu indikator kinerja yang berhubungan dengan hasil produksi, misalnya pengukuran produk yang cacat.

2. Stock Accuracy, yaitu indikator kinerja yang berhubungan dengan stok material maupun produk jadi.

3. Productivity, yaitu indikator kinerja yang berhubungan dengan 
produktivitas usaha, yaitu tingkat

produksi untuk menentukan reward atau insentif bagi tenaga kerja.

4. Sales dan work order, yaitu indikator kinerja yang berhubungan dengan penjualan dan rencana produksi.

Tabel 2a1. Key Performance Indicator Awal (Plan-Realibility)

\begin{tabular}{|c|c|c|}
\hline No. & Nama KPI & Definisi \\
\hline \multicolumn{3}{|c|}{ A. Plan } \\
\hline \multicolumn{3}{|c|}{ A.1 Reliability } \\
\hline 1. & $\begin{array}{l}\text { Finished } \\
\text { Goods } \\
\text { Inventory } \\
\text { Level }\end{array}$ & $\begin{array}{l}\text { Level inventory barang } \\
\text { jadi yang ada di gudang } \\
\text { dibandingkan dengan } \\
\text { seluruh output produk }\end{array}$ \\
\hline 2. & $\begin{array}{l}\text { Accuracy of } \\
\text { Forecast } \\
\text { Technique }\end{array}$ & $\begin{array}{l}\text { Tingkat ketepatan hasil } \\
\text { peramalan dengan tek- } \\
\text { nik peramalan yang ada }\end{array}$ \\
\hline 3. & $\begin{array}{l}\text { Percentages } \\
\text { of } \\
\text { Production } \\
\text { Unit to } \\
\text { Production } \\
\text { Planning }\end{array}$ & $\begin{array}{l}\text { Persentase kesesuaian } \\
\text { jumlah unit hasil pro- } \\
\text { duk dengan unit yang } \\
\text { direncanakan (work } \\
\text { order) }\end{array}$ \\
\hline 4. & $\begin{array}{l}\text { Internal } \\
\text { Relationship }\end{array}$ & $\begin{array}{l}\text { Hubungan antar bagian } \\
\text { dalam perusahaan seca- } \\
\text { ra internal yang dapat } \\
\text { mempengaruhi proses } \\
\text { perencanaan }\end{array}$ \\
\hline 5. & $\begin{array}{l}\text { Plan } \\
\text { Employee } \\
\text { Reliability }\end{array}$ & $\begin{array}{l}\text { Kehandalan tenaga } \\
\text { kerja yang terkait de- } \\
\text { ngan proses peren- } \\
\text { canaan }\end{array}$ \\
\hline
\end{tabular}

Sumber: Analisis Data Primer, 2018

Tabel 2a2. Key Performance Indicator Awal (Plan-Responsiveness)

\begin{tabular}{cll}
\hline No. & Nama KPI & \multicolumn{1}{c}{ Definisi } \\
\hline A.2 & Responsiveness \\
\hline 1. & $\begin{array}{l}\text { Planning } \\
\text { Cycle Time }\end{array}$ & $\begin{array}{l}\text { Waktu yang dibutuh- } \\
\text { kan untuk membuat } \\
\text { dan menyusun jadwal } \\
\text { produksi serta work } \\
\text { order }\end{array}$ \\
\hline 2. & $\begin{array}{l}\text { Time to } \\
\text { Revise } \\
\text { Production } \\
\text { Schedule }\end{array}$ & $\begin{array}{l}\text { Waktu yang dibutuh- } \\
\text { kan untuk merevisi } \\
\text { jadwal produksi jika } \\
\text { nuhi target }\end{array}$ \\
\hline 3. & $\begin{array}{l}\text { Time to } \\
\text { Identify New } \\
\text { Product } \\
\text { Specification }\end{array}$ & $\begin{array}{l}\text { Waktu yang dibutuhkan } \\
\text { untuk melakukan peneli- } \\
\text { tian dan pengembangan } \\
\text { produk baru }\end{array}$ \\
\hline
\end{tabular}

Sumber: Analisis Data Primer, 2018

Tabel 2b1. Key Performance Indicator Awal (Source-Reliability)

\begin{tabular}{lll}
\hline No. & \multicolumn{1}{c}{ Nama KPI } & \multicolumn{1}{c}{ Definisi } \\
\hline B. Source & \\
\hline B.1 & Reliability \\
\hline 1. & $\begin{array}{l}\text { Supplier Source } \\
\text { Fill Rate }\end{array}$ & $\begin{array}{l}\text { Prosentase jumlah pe- } \\
\text { rmintaan yang dapat } \\
\text { dipenuhi oleh supplier }\end{array}$ \\
\hline 2. & $\begin{array}{l}\text { Supplier } \\
\text { Delivery } \\
\text { Performance }\end{array}$ & $\begin{array}{l}\text { Prosentase tingkat ke- } \\
\text { tepatan waktu pengi- } \\
\text { riman order setelah } \\
\text { supplier }\end{array}$ \\
\hline 3. & $\begin{array}{l}\text { Percentages of } \\
\text { Quantity of } \\
\text { Order } \\
\text { Deliveries }\end{array}$ & $\begin{array}{l}\text { Prosentase ketepatan } \\
\text { jumlah unit pengiriman } \\
\text { sesuai dengan yang } \\
\text { dipesan dari supplier }\end{array}$ \\
\hline 4. & $\begin{array}{l}\text { Supplier have } \\
\text { Standardization }\end{array}$ & $\begin{array}{l}\text { Prosentase jumlah sup- } \\
\text { plier yang sudah memi- } \\
\text { liki standarisasi }\end{array}$ \\
\hline 5. & $\begin{array}{l}\text { Sources } \\
\text { Employee } \\
\text { Reliability }\end{array}$ & $\begin{array}{l}\text { Kehandalan tenaga ker- } \\
\text { ja yang terkait dengan } \\
\text { proses source }\end{array}$ \\
\hline Sumber: Analisis Data Primer 2018
\end{tabular}


Tabel 2b2. Key Performance Indicator Awal (Source-Responsiveness \& Flexibility)

\begin{tabular}{|c|c|c|}
\hline No. & Nama KPI & Definisi \\
\hline \multicolumn{3}{|c|}{ B.2 Responsivenes } \\
\hline 1. & $\begin{array}{l}\text { Purchase } \\
\text { Order Cycle } \\
\text { Time }\end{array}$ & $\begin{array}{l}\text { Waktu yang dibu- } \\
\text { tuhkan untuk me- } \\
\text { nertibkan pur- } \\
\text { chase order ke } \\
\text { supplier }\end{array}$ \\
\hline 2. & $\begin{array}{l}\text { Supplier } \\
\text { Delivery Lead } \\
\text { Time }\end{array}$ & \begin{tabular}{lr}
\multicolumn{2}{c}{ Waktu pengirim- } \\
an order oleh \\
supplier, mulai \\
dari memesan \\
sampai diterima \\
oleh kelompok \\
tani
\end{tabular} \\
\hline 3. & $\begin{array}{l}\text { Source } \\
\text { Responsive- } \\
\text { ness to } \\
\text { Supplier } \\
\text { Sustainability }\end{array}$ & $\begin{array}{l}\text { Waktu yang dibu- } \\
\text { tuhkan kelompok } \\
\text { tani untuk men- } \\
\text { cari supplier } \\
\text { pengganti apabila } \\
\text { supplier pertama } \\
\text { tidak bisa mem- } \\
\text { enuhi permintaan } \\
\text { kelompok tani }\end{array}$ \\
\hline 4. & $\begin{array}{l}\text { Supplier } \\
\text { Responsive- } \\
\text { ness to Order } \\
\text { Revision }\end{array}$ & $\begin{array}{l}\text { Waktu yang dibu- } \\
\text { tuhkan oleh sup- } \\
\text { plier untuk meme- } \\
\text { nuhi permintaan } \\
\text { jika terjadi per- } \\
\text { ubahan jumlah } \\
\text { permintaan }\end{array}$ \\
\hline
\end{tabular}

B3. Flexibility

\begin{tabular}{cll}
\hline 1. & $\begin{array}{l}\text { Minimum } \\
\text { Order } \\
\text { Quantity }\end{array}$ & $\begin{array}{l}\text { Jumlah minimal } \\
\text { kuantitas permin- } \\
\text { taan untuk setap } \\
\text { order yang bisa } \\
\text { dipenuhi supplier }\end{array}$ \\
\hline 2. & $\begin{array}{l}\text { Supplier } \\
\text { Flexibility of }\end{array}$ & $\begin{array}{l}\text { Volume jumlah peningkat- } \\
\text { Order }\end{array}$ \\
& $\begin{array}{l}\text { an permintaan } \\
\text { Quantity }\end{array}$ & $\begin{array}{l}\text { material yang bisa } \\
\text { dipenuhi supplier }\end{array}$ \\
\hline Sumber : & Analisis Data Primer, 2018
\end{tabular}

Tabel 2c. Key Performance IndicatorAwal

\begin{tabular}{lll}
\hline No. & \multicolumn{2}{c}{ Nama KPI } \\
\hline C. Make & \multicolumn{1}{c}{ Definisi } \\
\hline C.1 & Reliability & \\
\hline 1. & Yield & $\begin{array}{l}\text { Ratio perbandingan ant- } \\
\text { ara output dibagi input }\end{array}$ \\
\hline 2. & $\begin{array}{l}\text { Product } \\
\text { Failure in } \\
\text { Grinding } \\
\text { Process }\end{array}$ & $\begin{array}{l}\text { Prosentase produk yang } \\
\text { reject dari mesin grin- } \\
\text { ding }\end{array}$ \\
\hline 3. & $\begin{array}{l}\text { Product } \\
\text { Failure in } \\
\text { Mixer } \\
\text { Process }\end{array}$ & $\begin{array}{l}\text { Prosentase produk yang } \\
\text { reject dari mesin mixer }\end{array}$ \\
\hline 4. & $\begin{array}{l}\text { Machine } \\
\text { Efficiency }\end{array}$ & $\begin{array}{l}\text { Tingkat efisiensi mesin } \\
\text { yang digunakan pada } \\
\text { proses produksi }\end{array}$ \\
\hline 5. & $\begin{array}{l}\text { Make } \\
\text { Employee } \\
\text { Reliability }\end{array}$ & $\begin{array}{l}\text { Kehandalan tenaga kerja } \\
\text { yang dapat mendukung } \\
\text { jalannya proses produksi }\end{array}$ \\
\hline
\end{tabular}

\section{C.2 Responsiveness}

\begin{tabular}{lll}
\hline 1. & $\begin{array}{l}\text { Production } \\
\text { Lead Time }\end{array}$ & $\begin{array}{l}\text { Waktu yang dibutuhkan } \\
\text { untuk memproduksi 1 } \\
\text { unit produk }\end{array}$ \\
\hline 2. & $\begin{array}{l}\text { Machine } \\
\text { Set } U p\end{array}$ & $\begin{array}{l}\text { Waktu set up yang } \\
\text { dibutuhkan oleh mesin }\end{array}$ \\
Time & $\begin{array}{l}\text { pada saat mulai produksi } \\
\text { dan saat terjadi } \\
\text { perubahan setting produk }\end{array}$ \\
\end{tabular}

\begin{tabular}{|c|c|c|}
\hline 1. & $\begin{array}{l}\text { Production } \\
\text { Volume } \\
\text { Flexibility }\end{array}$ & $\begin{array}{l}\text { Prosentase peningkatan } \\
\text { jumlah produksi yang } \\
\text { bisa dipenuhi dalam } \\
\text { kurun waktu tertentu }\end{array}$ \\
\hline 2. & $\begin{array}{l}\text { Production } \\
\text { Item } \\
\text { Flexibility }\end{array}$ & \begin{tabular}{lcr}
\multicolumn{2}{l}{ Prosentase } & \multicolumn{2}{c}{ peningkatan } \\
jumlah & variasi & jenis \\
produk & yang & bisa \\
dipenuhi & &
\end{tabular} \\
\hline 3. & $\begin{array}{l}\text { Material } \\
\text { Substitubi- } \\
\text { lity }\end{array}$ & $\begin{array}{l}\text { Tingkat fleksibilitas } \\
\text { material produk untuk } \\
\text { dapat digantikan dengan } \\
\text { material lain }\end{array}$ \\
\hline
\end{tabular}

Sumber : Analisis Data Primer, 2018 
Tabel 2d. Key Performance Indicator Awal (Deliver)

\begin{tabular}{|c|c|c|}
\hline No. & Nama KPI & Definisi \\
\hline \multicolumn{3}{|c|}{ D. Deliver } \\
\hline \multicolumn{3}{|c|}{ D.1 Reliability } \\
\hline 1. & $\begin{array}{l}\text { Delivery Fill } \\
\text { Rate }\end{array}$ & $\begin{array}{l}\text { Prosentase unit } \\
\text { barang yang bisa } \\
\text { dipenuhi oleh } \\
\text { perusahaan }\end{array}$ \\
\hline 2. & $\begin{array}{l}\text { Number of } \\
\text { Quantity } \\
\text { Faultiness } \\
\text { Delivery } \\
\end{array}$ & $\begin{array}{lr}\text { Jumlah pengiriman } \\
\text { yang salah } & \text { secara } \\
\text { kuan-titas } & \text { ke } \\
\text { customer } & \\
\end{array}$ \\
\hline 3. & $\begin{array}{l}\text { Number of Item } \\
\text { Faultiness } \\
\text { Delivery }\end{array}$ & $\begin{array}{l}\text { Jumlah pengiriman } \\
\text { yang salah dilihat } \\
\text { dari jenis item yang } \\
\text { diminta ke customer }\end{array}$ \\
\hline
\end{tabular}

\begin{tabular}{|c|c|c|}
\hline 1. & $\begin{array}{l}\text { Delivery Fill } \\
\text { Rate }\end{array}$ & $\begin{array}{l}\text { Waktu yang } \\
\text { dibutuh-kan sejak } \\
\text { adanya per-mintaan } \\
\text { sampai kese-luruhan } \\
\text { barang diteri-ma } \\
\text { customer }\end{array}$ \\
\hline 2. & $\begin{array}{l}\text { Response to } \\
\text { Number of } \\
\text { Urgent }\end{array}$ & \begin{tabular}{l}
\multicolumn{2}{l}{ Kecepatan reaksi } \\
dalam menangani \\
adanya per-mintaan
\end{tabular} \\
\hline & Deliveries & $\begin{array}{l}\text { pengiriman yang } \\
\text { mendadak }\end{array}$ \\
\hline
\end{tabular}

D.3 Flexibility

\begin{tabular}{|c|c|c|}
\hline 1. & $\begin{array}{l}\text { Minimal } \\
\text { Delivery } \\
\text { Quantity }\end{array}$ & $\begin{array}{l}\text { Jumlah minimal } \\
\text { kuan-titas yang bisa } \\
\text { dipenuhi dalam } \\
\text { setiap pengirim-an }\end{array}$ \\
\hline
\end{tabular}

Sumber : Analisis Data Primer, 2018

Tabel 2e1. Key Performance Indicator Awal (Return-Reliability)

\begin{tabular}{|c|c|c|}
\hline \multicolumn{3}{|c|}{ E. Return } \\
\hline \multicolumn{3}{|c|}{ E.1 Reliability } \\
\hline 1. & $\begin{array}{l}\text { Supplier } \\
\text { Material } \\
\text { Defect Rates }\end{array}$ & $\begin{array}{l}\text { Prosentase rata-rata } \\
\text { jumlah material cacat } \\
\text { yang dikembalikan ke } \\
\text { supplier }\end{array}$ \\
\hline 2. & $\begin{array}{l}\text { Number of } \\
\text { Customer } \\
\text { Complaint }\end{array}$ & $\begin{array}{l}\text { Jumlah komplain atau } \\
\text { keluhan yang disam- } \\
\text { paikan oleh customer }\end{array}$ \\
\hline
\end{tabular}

Sumber : Analisis Data Primer, 2018
Tabel 2e2. Key Performance Indicator Awal (Return Responsiveness)

\begin{tabular}{lllr}
\hline \multicolumn{2}{c}{ No. } & \multicolumn{2}{c}{ Definisi KPI } \\
\hline E.2 & Responsiveness & \\
\hline 1. & Suppplier & Waktu yang dibutuh- \\
& Material & kan supplier & untuk \\
& Replacement & mengganti & material \\
& Time & yang cacat & \\
\hline 2. & Time to & Waktu yang dibutuhan \\
& Solve a & perusahaan r untuk \\
& Complaint & mengatasi komplain \\
& & dari customer \\
\hline
\end{tabular}

Sumber : Analisis Data Primer, 2018

Terdapat 3 tipe KPI yaitu larger is better, lower is better dan nominal is better. Pada tipe larger is better semakin besar nilainya maka dikatakan semakin baik, misalkan jumlah produk. Sedangkan pada tipe lower is better, semakin kecil nilainya maka dikatakan kinerja semakin baik, misalnya jumlah produk cacat, on time delivery dan cost.

\section{b. Agregat Nilai Performansi}

Setelah nilai indeks kinerja dari masing-masing KPI, maka akan dihitung agregasi (keseluruhan) nilai performansi perusahaan. Nilai performansi agregat adalah jumlah kerumsseluruhan dari perkalian bobot dan nilai. Normalisasi KPI dirumuskan: 
$N_{\text {agregate }}=\sum I k p i=\sum W_{i} x N_{i}$

dimana:

$\mathrm{N}_{\text {agregate }}=$ Nilai kinerja rantai pasok;

$\mathrm{I}_{\mathrm{kpi}}=$ Nilai indeks kinerja KPI ke-I; $\mathrm{W}_{\mathrm{i}}$

$=$ Nilai bobot KPI ke-i; Ni = Nilai

Normalisasi KPI ke-i

Nilai kinerja rantai pasok kelompok usaha tani diperoleh perhitungan untuk Periode bulan Agustus 2017 sampai Juli 2018 adalah sebagai berikut :

a. Product Failure in Grinding Process (PFGP) selama periode pengukuran Januari 2017 dan Maret 2018 KPI berwarna hijau tua selain itu KPI berwarna merah

b. Product Failure in Mixer Process (PFMP), di mana selama periode pengukuran hanya pada bulan Maret 2018 dan Mei 2018 berwarna hijau tua selain itu KPI banyak berwarna merah

c. Purchase Order Cycle Time (POCT), di mana sebagian besar KPI selama periode pengukuran maasih didominasi KPI berwarna merah

d. Machine Efficiency (MEF), di mana kinerja untuk KPI ini selama periode pengukuran cenderung menurun

e. Number of Customer Complaint (NCC), di mana selama periode pengukuran tingkat complain yang terjadi masih sangat tinggi

Tabel 3. Kinerja Rantai Pasok Kelompok Usaha Agustus 2017 - Juli 2018

\begin{tabular}{|c|c|c|c|c|c|}
\hline No. & $\begin{array}{l}\text { Bulan, } \\
\text { Tahun }\end{array}$ & NPA & No. & $\begin{array}{l}\text { Bulan, } \\
\text { Tahun }\end{array}$ & NPA \\
\hline 1. & $\begin{array}{c}\text { Agus, } \\
2017\end{array}$ & 65,06 & 7. & $\begin{array}{l}\text { Feb, } \\
2018\end{array}$ & 65,61 \\
\hline 2. & $\begin{array}{l}\text { Sept, } \\
2017\end{array}$ & 48,35 & 8. & $\begin{array}{c}\text { Maret, } \\
2018\end{array}$ & 64,28 \\
\hline 3. & $\begin{array}{l}\text { Okt, } \\
2017\end{array}$ & 63,79 & 9. & $\begin{array}{c}\text { April, } \\
2018\end{array}$ & 51,34 \\
\hline 4. & $\begin{array}{l}\text { Nop, } \\
2017\end{array}$ & 46,06 & 10. & $\begin{array}{l}\text { Mei, } \\
2018\end{array}$ & 53,32 \\
\hline 5. & $\begin{array}{l}\text { Des, } \\
2017\end{array}$ & 56,16 & 11 & $\begin{array}{l}\text { Juni, } \\
2018\end{array}$ & 64,43 \\
\hline 6 & $\begin{array}{c}\text { Jan, } \\
2018\end{array}$ & 44,27 & 12 & $\begin{array}{l}\text { Juli, } \\
2018\end{array}$ & 59,49 \\
\hline
\end{tabular}

Sumber: Analisis Data Primer, 2018

Tabel 4. Persebaran Indikator Performansi Tiap Bulan

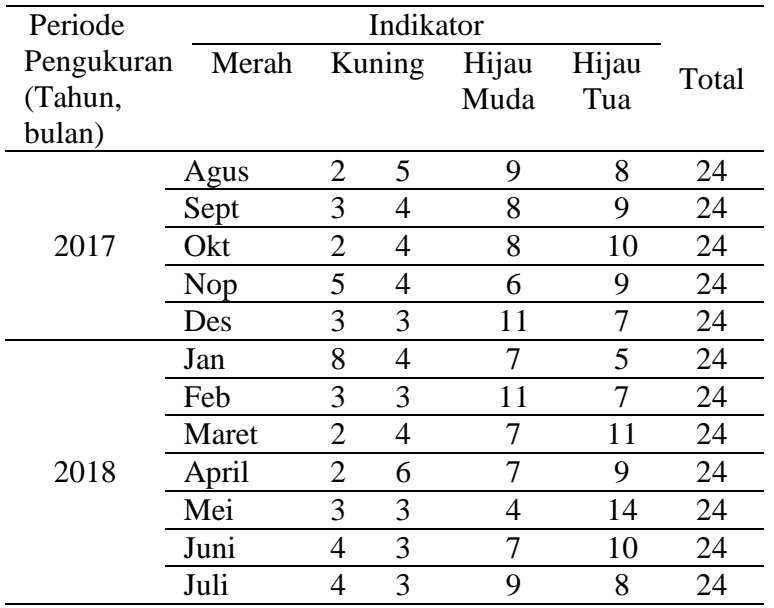

Sumber : Analisis Data Primer, 2018 


\section{KESIMPULAN DAN SARAN}

\section{Kesimpulan}

1. Rancangan sistem pengukuran kinerja rantai pasok tersebut sebagai berikut:

a. Identifikasi KPI berdasarkan SCOR model, sebanyak 39 KPI yang teridentifikasi yang teridentifikasi namun yang tervalidasi hanya $24 \mathrm{KPI}$

b. Hasil dari pembobotan: Plan $(0,233)$, Source $(0,120)$, Make $(0,555)$, Deliver $(0,060)$ dan Return (0,032). Serta 5 besar KPI dengan bobot tertinggi adalah MER (0,202), PCT $(0,200), \quad$ PFGP $(0,099), \quad$ PIF $(0,074)$ dan PLT $(0,066)$

2. Berdasarkan traffic light system KPI PFMP banyak mempunyai warna merah. Cacat yang biasa terjadi dalam proses mixing adalah cacat yang berhubungan dengan bahan baku yang tidak memenuhi standar mutu.

\section{Saran}

1. Diperlukan penambahan divisi supply chain di mana divisi ini mengurusi masalah yang berhubungan dengan internal rantai pasok perusahaan.
2. Pengukuran kinerja rantai pasok harus dilaksanakan secara periodik fungsinya adalah agar kelompok tani mengetahui letak kelebihan dan kelemahannya sehingga pada saat indikator kinerja menunjukkan penurunan bisa diambil langkah perbaikan.

\section{DAFTAR PUSTAKA}

Chopra, S., and M. Peter. 2011. Supply Chain Management Strategy Planning and Operation. New Jersey. Prentice Hall, Inc.

Klapper, L. , and N. Hamblin. 2010. Supply Chain Management: A Recommended Performance Measurement Scorecard. Department of Defense USA.

Pires, S., R.I. Aravechia, and H.M. Carlos. 2011. Measuring The Supply Chain Performance. Proceeding of Twelfth Annual Conference of The Production and Operation Management Society. POM-2011. March 30 ${ }^{\text {th }}$ - April $2^{\text {nd }}$. Orlando.

Pujawan, I N. 2015. Supply Chain Management. Surabaya. Guna Widya.

Trienenkens, J.H., and H. Hvolby. 2015.

Performance Measurement and Improvement in Supply Chain. CINET Conference. 